\title{
The Effect of Asthma patient Education on Reducing Hospital Admissions
}

\author{
Dr. Omar Z. Alsharqi \\ Department of Health Services and Hospitals \\ Faculty of Economics and Administration - King Abdulaziz \\ University - Jeddah- Saudi Arabia
}

Nouf, Alhelaisy

Faculty of Economics and Administration

King Abdulaziz University Jeddah- Saudi Arabia 


\section{Abstract}

Patient education is important for good health; it is also a foundation for the prevention of various chronic conditions. Asthma is among the least explored in terms of patient education. Hospital admissions are the result of poor education, a lack of adherence to medication and treatment, and failure to attend regular check-ups. Patients lack both awareness of the factors that predispose them to asthma and the means of treatment and prevention. Increased hospital admissions also lead to higher expenses. The purpose of the research is to explore the influence of asthma patient education on hospital admissions. The research objectives were achieved through a review of current studies on social learning and cognitive theories, and an investigation into how asthma-related knowledge relates to patient education. The sample population included patients diagnosed with asthma from King Saud Medical City in Riyadh. The method involves purposive sampling. The most important results are: the need to engage patients in educational programs to decrease the incidence of complications and reduce hospital admission rates; the need to provide instructions regarding the correct use of tools and strategies in order to avoid adverse risks; the importance of nurses' and physicians' roles in controlling asthma in order to reduce hospitalization; appropriate knowledge among asthma patients' families improves the efficiency and quality of healthcare offered by physicians and nurses, thus decreasing hospital admissions; and providing patients with theoretical knowledge and practical expertise is likely to decrease hospital admissions and ensure they can care for themselves at home. The key recommendations are: to introduce new educational programs in order to provide patients with useful data regarding medications and the use of asthma-related tools; to 
develop learning methods by helping patients to understand care, medications, the correct use of tools and warning signs, delivered in a format that includes demonstrations of care, teach-back questions and assessments, and that facilitates provider communications; to develop an action plan for patients that is linked with the Electronic Medical Record to allow nurses and physicians to monitor patients' progress remotely and ensure this plan is followed; and to enhance patients' and families' knowledge by offering full participation in their own healthcare and encourage them to partner with clinicians to increase their adherence to disease management in order to become more accountable for their own health.

Keywords: Asthma, Patient Education, Hospital Admissions, Saudi Arabia 
يعد التثقف الصحي من المور الهامة للصحة الجيدة ؛ وكذلك فهو أساس للوقاية من مختلف الأمر اض المزمنة. ويعد مرض الربو من أهم الأمر اض التي تم استكثافه من خلال تثقيف المرضى. يعد الدخول إلى المستشفى نتيجة لضعف التثقيف الصحي و عدم الالتز ام بالوصفة الطبية والعلاج، و عدم المداومة على الفحوصات الدورية. يترتب على ضعف وعي المرضى بالعو امل التي تقيهم من مرض ووسائل العلاج و الوقاية منه زيادة نردد مرضى الربو على المستشفيات مما يؤدي الى ارتفاع تكاليف الرعاية الصحية. الهدف من هذا البحث هو استكثاف تأثثير تثقيف مرضى الربو على معدلات التردد على المستشفيات و التنويم، ولتحقيق أهداف البحث من تم مر اجعة الدر اسات السابقة حول التعليم الاجتماعي والنظريات المعرفية، والتحقق من كيفية ارتباط المعرفة بالربو المستفادة من التنقيف الصحي للمريض. تضمنت العينة عينة البحث مرضى مصابون بالربو من مدينة الملك سعود الطبية بالرياض، وتم تحديد العينة اعتمادا على اسلوب العينة الهادفة. توصل البحث الى عدة نتائج أههها: الحاجة إلى إثر الك المرضى في البر امج التثقيف الصحي لتقليل حدوث المضاعفات وتقليل معدلات الدخول في المستشفيات؛ الحاجة إلى تقديم الإرشادات المتعلقة بالاستخدام الصحيح للأدوات و الاستراتيجيات لتجنب المخاطر السلبية لمرض الربو؛ أهمية دور الممرضين والأطباء في السيطرة على الربو من أجل الحد من دخول المستشفى؛ التثقيف الصحي المناسب بين عائلات مرضى الربو بساعد في تحسين كفاءة ونوعية الرعاية الصحية المقدة من قبل الأطباء و الممرضات، مما يقلل من حالات الدخول المستشفيات؛ توفير المعرفة النظرية والخبرة العملية للمرضى بساعد في تقليل حالات دخول المستشفى وضمان قدرتهم على رعاية أنفسهم في المنزل. وتتمثل التوصيات الرئيسية في: تقديم برامج تتقيف صحي جديدة من أجل تزويد المرضى ببيانات مفيدة عن الأدوية واستخدام الأدوات المتعلقة بالربو. تطوير طرق التقيف الصحي التي تساعد المرضى على فهم الرعاية والأدوية و الاستخدام الصحيح للأدوات و علامات التحذير، و التي يتم تقديمها في صيغة تتضمن مظاهر الرعاية و الاستفسار ات و التقييمات التقييمات التي تسهل علاقات المريض بمقدم خدمات الرعاية الصحية ؛ وضع بر امج تثقيف للمرضى منعلقة بالسجل الطبي الإلكتروني للسماح للممرضات و الأطباء بمر اقبة تقدم المرضى عن بُعد والتأكد من استمرارية|تباع هذه الخطط العلاجية عن بعد؛ وتعزيز معرفة المرضى وعائلاتهم من خلال المشاركة الكاملة في الرعاية الصحية الخاصة بهر وتشجيعهم على المشاركة مع الأطباء لزيادة التز امهم بإدارة المرض ويصبحوا أكثر تحملا للمساءلة عن صحتهم. 


\section{Introduction}

Asthma is a serious public health problem whose prevalence has been increasing over the last few years in most parts of the world. It is estimated that 30 million people will be diagnosed with asthma at some point in their life. From 2001 to 2011, the number of individuals with asthma increased by $28 \%$. ${ }^{[1]}$ This is significant as it implies an increased burden both to the healthcare system and society as a whole, due to the high costs associated with managing the condition.

Asthma has been identified as the most common chronic childhood condition and it impacts not only the affected child, but the family as a whole. ${ }^{[2]}$ Asthma can have a detrimental impact on the affected child, both physiologically and emotionally. Successful management, therefore, involves both medication for the physical symptoms and dealing with the associated stressors. ${ }^{[3]}$ These stressors include emotions such as grief, despair, fear, confusion, uncertainty and anger.

Asthma has been increasing in prevalence despite advancements in both pathophysiology and treatment. Many people die as a consequence of asthma and related complications. ${ }^{[1]}$ This also applies in Saudi Arabia. Factors that account for most of this morbidity include inadequate knowledge of the condition and its treatment, inadequate knowledge of inhalers and their use, and inadequate self-management. ${ }^{[4]}$ These factors serve as evidence for the necessity of patient education.

Patient education is the key to promoting health by emphasising disease management. This involves providing patients and their families with the information necessary to manage their condition. ${ }^{[5]}$ Patient education is a process that encompasses assessment, planning, 
implementation and evaluation. This is significant as this implies that patient education is a systematic process of learning. It is considered the duty of healthcare professionals (physicians or nurses) to offer patients education about their condition. ${ }^{[6]}$ Emphasis has been placed on the need for these professionals to be able to facilitate this education. In particular, they need to be better positioned to assess the learning needs of patients, to determine appropriate teaching methods and evaluate learning achievements.

Patient education is therefore a critical component of asthma management. It has become a vital area of service provision, especially as the population of individuals with chronic conditions needing long-term management within the community has increased. ${ }^{[7]}$ Studies have been undertaken to evaluate the effects of patient education, which revealed that denial of asthma, lack of knowledge about the disease process and its treatment, and insufficient self-management indicate a lack of education about asthma. ${ }^{[5,8]}$ This has had an impact on the morbidity of asthma and has been a leading cause of many patients being unable to care for themselves following asthmatic episodes. As a result, there has been an increase in asthma-related hospital admissions despite the development of many more preventer drugs. ${ }^{[9]}$ In Saudi Arabia, for instance, the rate of asthma-related hospital admissions has risen considerably, with each year recording higher figures of asthma diagnosis. There is also evidence of an increase in the severity and prevalence of asthma in many other countries. This is further evidenced by the increasing costs associated with the treatment and management of asthma, including the increased costs of drugs. ${ }^{[3]}$ The severity of asthma can be determined by analysing hospital 
admissions, in particular by measuring the time spent in hospital. It has been shown that a hospital admission serves as a strong indicator of the severity of asthma. ${ }^{[10]}$ It is also an indicator of likely readmissions and eventual death.

Comprehensive, individualized asthma education is critical to the reduction of the high hospitalization rates that have been witnessed. Specifically, it is important that focus is placed on educating patients about

self-care. ${ }^{[11]}$ Self-management is essential to reducing the impact of chronic conditions and consequently improving the quality of life. This study will therefore explore the effects of patient education on asthma to determine its impact on the reduction of hospital admissions.

\section{Literature Review}

\subsection{Social Cognitive Theory}

Social cognitive theory (SCT) posits that people learn through observation. This process is defined as a vicarious or modelling process of learning, in which learning arises as a consequence of how others behave and the impact of existing models within the environment. This theory therefore suggests that learning depends considerably on the availability of models. This is significant in relation to this study as it implies that patient education can be facilitated through the development of appropriate models. These can be in the form of live demonstrations by a teacher of the behaviour to be learned, or in audio and video format.

SCT postulates that the process of observational learning depends on a number of interrelated processes comprising attention, retention, production and motivation. Attention to a given model and relevant behaviour is vital for learning. Retention refers to the processes that are needed to oversee the 
reduction and transformation of what is to be observed into something that is symbolic. This is then stored for use at a later time. Production is the process by which students draw on their stored codes and perform what they have observed. Motivation is vital for fostering an understanding of the reasons why students engage in the previous sub-processes. It is essential to note, however, that each of these processes is affected by a number of factors. These include the particular level of a person's development as well as the specific characteristics of the model that is to be used to shape behaviour. This study will consider these processes in relation to asthma patient education.

\subsection{Social Cultural Learning}

Social cultural learning theory explores the relationship between the social world and cognitive development. It argues that the process of learning goes beyond the simple transfer of information from a source such as a teacher or parent, to involve an active process of social interaction. This can entail the construction of knowledge through the process of experimentation and discovery, which is significant in relation to this study. The advancement of this theory was undertaken by giving particular attention to the relationship between macro- and micro-social influences on the process of cognitive development.

Vygotsky, in the advancement of the social cultural theory, paid close attention to the social world. The social world here consists of more than the interaction between a student and a teacher, and instead consists of much broader socio-cultural historical influences on the learning process and environment. The main themes of this theory have been presented in the following summary: (a) the significance of culture, (b) the role of 
language as a major promoter of culture, (c) the student's relationship with this social world.

Culture is perceived as those socially accepted behaviours, attitudes and beliefs which are developed using various human societal products, including systems of symbols, tools of language and institutions. Furthermore, culture is perceived as a dynamic outcome of historical events. Vygotsky therefore opined that culture has the capacity to influence mental functioning and behaviour.

Social cultural learning theory explores the concept of internalization. Internalization is a process involving the internal acceptance of social values, beliefs and attitudes. This theory asserts that internalization alters the individual's psychological makeup, therefore providing a dynamic mechanism through which the inter-social transforms into the intra-social. In other words, internalization results in interpersonal cultural influences being transformed into intrapersonal characteristics. This implies that every function within a child's cognitive development including attention, concept formation and logic appears twice, initially on the social level, then proceeding to the individual level. This shows that there is adequate opportunity within the learning process to influence the cognitive functioning of learners through patient education.

\subsection{Multiple Intelligences Theory}

Multiple intelligences theory divides intelligence into specific modalities, rather than seeing it as a single general-ability perspective. This theory applies concepts of cognition, sociology and anthropology to explore and explain human intellect, and advances nine different forms of intelligence. These are identified through eight established criteria: (a) 
isolation emanating from brain damage, (b) the availability of prodigies and people with high levels of intellect, (c) core operations that are distinguishable, (d) stages of development with an end state that is expert in nature (e) the history of evolution and plausibility, (f) the propensity to encode in a symbol system, (g) support emanating from psychological tasks that are experimental, (h) psychometric research support.

Multiple intelligences theory has been vital in challenging the traditional and narrower perceptions of intelligence. For instance, previously advanced ideas about intellectual ability have posited that a person's intelligence can be viewed as a constant over their lifetime. Furthermore, it has also been contended that intelligence is something that could be measured utilizing a person's logical and language abilities. However, for this theory, intelligence comprises the capacity to create and develop solutions for problems and create products that are of value to society.

Multiple intelligences theory posits that people have nine forms of intelligence, though in varied levels. Every person has an intelligence profit that is distinct and represents them and their ability to learn. Accordingly, an assessment of the level of intelligence shown by a student's profile could be significant in the enhancement of education. It may also facilitate the design of appropriate activities. This is significant for this study as it implies that an assessment of the level of intelligence of patients can serve to improve their asthma education. Each form of intelligence as per this theory is located in a different part of the brain.

Furthermore, the nine determined forms of intelligence may function in partnership with each other or operate individually. This theory, therefore, provides an explanation for the differences experienced in the 
learning processes of students. In particular, it explains the different strengths and weaknesses that are witnessed in learning. These learning differences should be taken into consideration when developing education programs to ensure their effectiveness. The nine forms of intelligence are defined as: verbal/linguistic, mathematical/logic, visual, bodily/ kinaesthetic, musical, interpersonal, intrapersonal, naturalistic, and existential. It should be noted that existential intelligence has yet to be fully accepted by educators. Additional research is therefore required to enable this definition of intelligence to become more acceptable.

Multiple intelligences theory can be incorporated into patient education in a number of ways, including the establishment of various learning centres with resources and materials to encourage the involvement of different intelligences. This could entail the development of simulations that immerse patients in real-life situations concerning asthma and its impact on their lives. Careful planning is needed in order to ensure quality as well as patient learning. Furthermore, instructional models like projectbased and collaborative learning can be easily integrated into lessons to take account of multiple intelligences. Collaborative learning serves to allow students to explore their sense of personal intelligence, whilst project-based learning assists in the structuring of activities that foster the cultivation of the nine identified forms of intelligence.

\subsection{Asthma Patient Education Programs}

Asthma patient education programs are one of the most effective methods of ensuring patients remain healthy and are not hospitalized. Asthmatic patients should engage in educational programs that show them the correct measures to put in place to ensure their quality of life. Such 
programs are essential in order to reduce hospital admission rates and consequent expenses. ${ }^{[12]}$

Al-Muhsen et al. ${ }^{[12]}$ report that most patients who have multiple admissions have not been educated in controlling their condition. This is due to their management action plan not being implemented correctly. Poor knowledge contributes to an increase in emergency cases especially following exposure to asthma triggers. These scholars, therefore, recommend that patients are engaged in continuous assessment and education for the condition they suffer from. According to Al-Muhsen et al. ${ }^{[12]}$ healthcare settings should provide such educational programs and set standards to prevent readmission. Before discharge, patients should have a face-to-face talk with their physicians about the importance of taking their medication as prescribed, and how to avoid foods that could cause harm.

\subsection{Asthma Patient Knowledge}

Asthma education helps patients to self-manage their condition. It is the mandate of every hospital to ensure that patients receive personalized advice to enable them to optimize this self-management. Pinnock (2015) discusses the need for such educational programs with regards to handling cases of asthma attacks and indicates that patients need to understand their condition and incorporate methods that will help them to live with this disease on a daily basis. ${ }^{[13]}$ It is imperative that patients remember to carry their inhalers and medication, and that they avoid the triggers that can cause attacks. Moreover, patients need to understand the variability of asthma and the impact of other people's lifestyles on their condition. Selfmanagement of asthma in patients is necessary, as indicated by Pinnock ${ }^{[13]}$, who argues that patients need to understand when their condition is 
deteriorating and adjust their medication accordingly, and that they need to recognize when they need immediate treatment. Pinnock ${ }^{[13]}$ undertook surveys which showed that about three-quarters of people affected manage their condition without having an action plan from the doctors. Therefore, Pinnock [13] advocates for self-management education as the most appropriate method to reduce the adverse outcomes of asthma and indicates that each patient should understand the severity of their disease and abide by their physician's instructions.

Axelsson, Ekerljung, and Lundbäck (2015) investigated the importance of follow-ups from nurses and physicians to the promotion of healthy lifestyles. ${ }^{[14]}$ Questionnaires were given to 165 adults who had been diagnosed as asthmatic. These findings showed that nurses and physicians have multiple roles in ensuring patients remain healthy and have a good quality of life.

Nurses should ensure that patients abide by the care plan provided. It is imperative that practitioners ensure their patients understand the need to follow this plan and take all the required medication to reduce their symptoms. The action plan, as discussed by Axelsson et al. ${ }^{[14]}$ stipulates all the requirements, including foods and medications that the patient should have. Additionally, physicians have to ensure that patients and their caregivers are educated in how to avoid the causative agents of the disease, as well as control it in the case of an emergency. Controlling the causative agents of asthma helps to reduce the chances of hospitalization by reducing irritation.

Finally, nurses and physicians should conduct regular visits and assessments to ensure patients are taking their medication. They will 
therefore understand the chances of the patient having adverse attacks and advise them appropriately in order to obtain better outcomes.

A Chinese study indicates that asthma is a condition that is becoming increasingly prevalent among children. According to Zhao, Shen, Xiang, Zhang, Xie, Bai, and Chen (2013), parents have insufficient knowledge of the disease, and their inappropriate management practices lead to a reduced quality of life for their children. ${ }^{[15]}$

Zhao et al (2013) propose that family members of asthma patients should undergo training in how to treat the patient in the case of an emergency and how to prevent such an outcome. ${ }^{[15]}$ The management of this disease should not only be thoroughly undertaken by both the patient and the healthcare practitioners, but the burden should also be shared among other stakeholders. The study indicates that the increase in asthma in children has caused a rise in morbidity and mortality, and reduced their quality of life, and therefore suggested that all parents of children faced with chronic disease are educated about its impact on the child's life, how to control it and how to prevent adverse outcomes.

According to Carrillo, Perez-Patron, Lucio, Cabrera, Trevino, $\mathrm{Xu}$, and Mier (2017) the education of parents will help to reduce hospital admissions. ${ }^{[16]}$ They also contend that such education programs help to promote quality of life and increase the chances of survival. This is especially important for families that live on less than average pay, for whom medical bills can be unaffordable. Moreover, Zhao, et al ${ }^{[15]}$ argue that hospitalizing children may cause other diseases by exposing their weak immune systems to multiple health issues. 


\section{Research Problem}

Asthma has been identified as one of the largest hospitalizationrelated expenses, and asthma-related hospital admissions have risen significantly over the last few years. This trend has mainly arisen due to the high level of ignorance among asthmatic patients, thus implying that patient education is limited. To some extent, this can be attributed to the fact that the impact of patient education on the reduction of hospital admissions for asthma is an area that is yet to be adequately investigated.

Existing studies have found that most asthma-related hospital admissions are preventable. These admissions occur mainly as a consequence of inadequate management, lack of adherence to treatment and medication, and failure to attend check-ups and follow-ups. Acute cases of asthma can be prevented through increased focus on patient education, nonetheless, the extent of this impact remains unclear. One thing that is apparent is that delayed education results in rather minimal positive outcomes. This can to a certain degree be attributed to the fact that asthma patient education inadequately describes the necessary learning and teaching principles that underpin the patient education process. The current study aims to investigate the extent to which patient education about asthma can facilitate the reduction of hospital admissions.

\section{Research Importance}

This study is essential to show how patient education can be used to foster the management of asthma and potentially reduce hospital admissions, thereby improving health outcomes for those affected. Providing patients with education, particularly with regard to the management of their condition, has been found to considerably reduce 
hospital admissions. Moreover, continued education following discharge has been found to have the most positive impact on admission rates. The significance of this study lies in the need to reduce pressure on healthcare facilities as a result of excessive asthma-related hospital admissions. This study will also be significant in illustrating the extent and consequences of the burden placed on the healthcare system and society by asthma-related hospital admissions.

\section{Research Objectives}

The objective of this study is to investigate the effects of asthma patient education on the reduction of hospital admissions. The research objectives are:

- To investigate the impact of asthma on hospital admissions.

- To determine how asthma patient education can be used to reduce hospital admissions.

\section{Research Methodology}

\subsection{Research Design}

In order to explore the impact of asthma patient education on the reduction of hospital admissions in King Saud Medical City, this study takes a form of descriptive analytical research. The goal is to obtain complete and accurate information while avoiding bias and maximizing reliability, in order to make a critical evaluation of the material. The methods utilized in descriptive research include comparative and correlational methods of survey.

A questionnaire was used to gather data from asthmatic patients who were admitted to the hospital, in order to find out the impact of the independent categories (Patients' and Families' Knowledge, Learning 
Methods, Physicians' and Nurses' Roles, Patient Education Program) on the dependent variable (Hospital Admissions).

\subsection{Population and Sampling}

The targeted sample for this study were diagnosed asthma patients. The specific sample method is a convenience sample $(n=100)$. This is appropriate for this kind of study, which targets one diagnosis such as asthma, and facilitates the reduction of bias in the selection of the sample size. The population of this study consisted of all asthmatic patients who were admitted during the period from December 3rd, 2017 to March 1st, 2018. King Saud Medical City is a Ministry of Health tertiary hospital located in Riyadh City which has a total capacity of 1415 beds.

\subsection{Research Variables}

The research variables come in the form of dependent and independent variables. The dependent variable, which is usually of the most interest, is Hospital Admissions. Therefore, this study will attempt to measure the changes in Hospital Admissions.

The independent variable is patient education. It is defined as the variable that affects the dependent variable. Patient education is therefore the variable that will need to be manipulated in this study to affect hospital admissions. That is to say, should patient education be conducted? To what extent will this cause a reduction in hospital admissions? In other words, the independent variable is that which a researcher is able to control.

The independent variables relating to patient education are defined as follows: Learning Methods are a 'distinctive and habitual manner of acquiring knowledge, skills or attitudes through study or experience'; Physicians' and Nurses' Roles refers to enhancing the accuracy of the 
diagnosis and increasing the patient's knowledge about the disease; Patients' and Families' Knowledge is an interdisciplinary and collaborative process designed to meet the needs of the individual patient throughout the continuum of care; and Patient Education Program refers to the presence of such a program at the hospital.

\subsection{Research Hypotheses}

The research hypotheses that have been determined for this study are as follows:

- There is a significant relationship between Patient Education Program and Hospital Admissions

- There is a significant relationship between Learning Methods and Hospital Admissions

- There is a significant relationship between Physicians' and Nurses' Roles and Hospital Admissions

- There is a significant relationship between Patients' and Families' Knowledge and Hospital Admissions

\subsection{Instrument}

The instrument is in the form of a quantitative questionnaire which was designed by the researcher on the basis of her review of the literature and her clinical experience. The questionnaire items were constructed to be relevant to the context of asthmatic patients' admissions to the hospital. The complete questionnaire has six sections comprising 31 questions and statements as shown in Appendix A.

The first section of the questionnaire contains four questions (1-4) to determine the gender, age, educational level and occupation. The second to 
fifth sections contain twenty-three statements (5-27) which determine patient education as the independent variable.

The second section contains six statements (5-10) which were asked to determine Patients' and Families' Knowledge as an independent variable. The third section (11-15) determines Learning Methods as an independent variable. Seven statements (16-22) in the fourth section were presented to determine the Physicians' and Nurses' Roles as an independent variable. In the fifth section, five statements (23-27) were presented to determine Patient Education Program as an independent variable.

The final section contains four statements (28-31) to which respondents were asked to state their level of agreement. These statements determine Hospital Admissions as the dependent variable.

A five-point ordinal Likert scale was used by respondents to rate the degree to which they agree or disagree with a statement. Responses are ranked from 1-5, where 1 represents 'strongly disagree', 2 represents 'disagree', 3 represents 'neutral', 4 represents 'agree', and 5 represents 'strongly agree' for positive statements as indicated in Table 1.

Table 1: Score of perception statements and weight ranges

\begin{tabular}{|c|c|c|c|c|c|}
\hline & \multicolumn{2}{|c|}{ Negative Perception } & Neutral & \multicolumn{2}{c|}{ Positive Perception } \\
\hline $\begin{array}{c}\text { Questionnair } \\
\text { e Statements }\end{array}$ & $\begin{array}{c}\text { Strongly } \\
\text { Disagree }\end{array}$ & Disagree & Neutral & Agree & $\begin{array}{c}\text { Strongly } \\
\text { Agree }\end{array}$ \\
\cline { 2 - 6 } & 1 & 2 & 3 & 4 & 5 \\
\hline $\begin{array}{c}\text { Likert Scale } \\
\text { Weight } \\
\text { Range }\end{array}$ & $(1-1.80)$ & $(1.81-2.60)$ & $(2.61-3.40)$ & $(3.41-4.20)$ & $(4.21-5)$ \\
\hline
\end{tabular}

\subsection{Validity and Reliability}

before the final questionnaire was distributed to the respondents, it was reviewed by professional academic staff and a specialist statistician. In 
addition, the researcher analysed the statements for each variable using the Correlation test by Person as shown in Table 2 .

Table 2: Person correlation among variables' statements

\begin{tabular}{|c|c|c|c|c|c|c|c|c|c|}
\hline \# & $\begin{array}{c}\text { Hospital } \\
\text { Admission }\end{array}$ & \# & $\begin{array}{c}\text { Patient } \\
\text { Education } \\
\text { Program } \\
\text { Statements }\end{array}$ & \# & $\begin{array}{c}\text { Learning } \\
\text { Methods } \\
\text { Statements }\end{array}$ & \# & $\begin{array}{c}\text { Physicians' } \\
\text { \& Nurses' } \\
\text { Roles } \\
\text { Statements }\end{array}$ & \# & $\begin{array}{c}\text { Patients' } \\
\text { and } \\
\text { Families' } \\
\text { Knowledge } \\
\text { Statements }\end{array}$ \\
\hline 1 & $0.925 * *$ & 1 & 0.722** & 1 & $0.663^{* *}$ & 1 & 0.670** & 1 & $\mathbf{0 . 7 7 9} * *$ \\
\hline 2 & 0.858** & 2 & $0.576 * *$ & 2 & $0.757 * *$ & 2 & $0.646 * *$ & 2 & 0.788** \\
\hline 3 & $0.904 * *$ & 3 & $0.995 * *$ & 3 & 0.883 ** & 3 & $0.646^{* * *}$ & 3 & $0.954 * *$ \\
\hline 4 & $0.857 * *$ & 4 & 0.751** & 4 & $0.602 * *$ & 4 & $0.617 * *$ & 4 & $0.910 * *$ \\
\hline & & 5 & 0.778** & 5 & 0.786** & 5 & $0.899 * *$ & 5 & $0.810 * *$ \\
\hline & & & & & & 6 & $0.994 * *$ & & 0.670 *** \\
\hline & & & & & & 7 & $0.832 * *$ & & \\
\hline
\end{tabular}

** Correlation is significant at the 0.01 level.

In this table the correlation for Hospital Admission statements was very strong, ranging between $0.857-0.925$, while the correlations for the Patient Education Program statements, Learning Methods statements, Physicians' \& Nurses' Roles statements and Patients' and Families' Knowledge statements were between moderately strong to very strong, ranging between $0.576-0.995,0.602-0.883,0.643-0.899$ and $0.670-$ 0.954 respectively. Based on this, a moderate to very strong correlation between the variable statements was observed.

The validated questionnaire was given to the respondents, and the pilot study was conducted with a sample size of twenty-five. The purpose of this pilot study is to test for comprehensibility and understanding. The respondents were also asked to point out any confusing or misleading questions or statements and ambiguous terms. This study is also intended to test the reliability of the questionnaire. A reliability test is needed to see the relatedness of the questionnaire variables for this study. This ensures that 
the information produced is clear, consistent and meaningful. Coefficient alpha (also known as Cronbach's alpha) is used to determine reliability.

Table 3: Cronbach's alpha for first and second round reliability

\begin{tabular}{|c|l|c|c|c|}
\hline No. & \multicolumn{1}{|c|}{ Domains } & $\begin{array}{c}\text { No. of } \\
\text { Statements }\end{array}$ & $\begin{array}{c}1^{\text {st }} \\
\text { Round }\end{array}$ & $2^{\text {nd }}$ Round \\
\hline 1 & $\begin{array}{l}\text { Hospital Admission } \\
\text { Statements }\end{array}$ & 4 & $\mathbf{0 . 8 8 6}$ & $\mathbf{0 . 8 9 4}$ \\
\hline 2 & $\begin{array}{l}\text { Patient Education Program } \\
\text { Statements }\end{array}$ & 5 & 0.764 & 0.773 \\
\hline 3 & $\begin{array}{l}\text { Learning Methods } \\
\text { Statements }\end{array}$ & 5 & $\mathbf{0 . 7 3 8}$ & $\mathbf{0 . 7 4 5}$ \\
\hline 4 & $\begin{array}{l}\text { Physicians' \& Nurses' Roles } \\
\text { Statements }\end{array}$ & 7 & $\mathbf{0 . 7 5 8}$ & $\mathbf{0 . 7 6 4}$ \\
\hline 5 & $\begin{array}{l}\text { Patients' and Families' } \\
\text { Knowledge Statements }\end{array}$ & 6 & $\mathbf{0 . 8 1 9}$ & $\mathbf{0 . 8 2 3}$ \\
\hline \multicolumn{2}{|r|}{ Total } & 27 & $\mathbf{0 . 7 8 8}$ & $\mathbf{0 . 7 9 5}$ \\
\hline
\end{tabular}

The consistency of the questionnaire was determined using alpha coefficients (Cronbach's alpha for reliability analysis) and was tested in two rounds. The alpha coefficients obtained for all sections of the questionnaire are above 0.738 , the overall reliability of the questionnaire being $r=0.788$ and 0.795 . Adopting an alpha of $r=0.700$ as an acceptable criterion for the reliability of scores on this scale meant that these scores could be considered reliable. ${ }^{[17]}$

For this research all the sections tested have shown a reliability value above 0.700 and the overall reliability $(0.788$ and 0.795$)$ in the two rounds is considered high and acceptable. As no confusing or misleading question or statement was highlighted, no changes were made for the actual research.

\subsection{Data Collection}

Research data were derived from diagnosed asthma patients in King Saud Medical City. The researcher visited the hospital's inpatient units and submitted the questionnaire to the potential respondents. The researcher 
provided her contact details in the questionnaire for any queries. The questionnaire was completed during the respondents' admission. Data collection commenced on December 3rd, 2017 and lasted until March 1st, 2018. One hundred questionnaires $(100 \%)$ were returned to the researcher after completion.

Respondents were informed that the survey was for academic purposes only and they would incur no risk. Names and identities were not required. They were fully informed that all data gathered would remain confidential.

\subsection{Data Analysis}

The data was analysed using the Statistical Package for Social Sciences (SPSS) Version 22.0 for Windows. A simple descriptive statistic was used to define the characteristics of the study variables through a form of mean and standard deviation. A chi-square test was used to examine the relationship between Patient Education Program, Learning Method, Physicians' and Nurses' Roles, Patients' and Families' Knowledge, and Hospital Admissions.

The validity of the statements for each variable was analysed using the Correlation test by Person while the reliability of the questions and statements was analysed via Cronbach's alpha to remove confusing or misleading questions or statements.

\section{Results and Discussion}

\subsection{Demographic characteristics of the respondents}

Respondents' personal and demographic characteristics that are examined are gender, age, educational level and occupation. A total of 100 completed questionnaires were analysed. 
Table 4: Distribution of respondents by personal characteristics

\begin{tabular}{|c|c|c|c|}
\hline $\begin{array}{c}\text { Personal } \\
\text { Characteristics }\end{array}$ & Group Item & Frequency & Percentage \\
\hline \multirow{3}{*}{ Gender } & Male & $\mathbf{1 5}$ & $\mathbf{1 5 \%}$ \\
\cline { 2 - 4 } & Female & $\mathbf{8 5}$ & $\mathbf{8 5 \%}$ \\
\hline \multirow{4}{*}{ Age } & $\mathbf{1 8 - 2 5}$ Years & $\mathbf{4 8}$ & $\mathbf{4 8 \%}$ \\
\cline { 2 - 4 } & $\mathbf{2 6 - 4 9}$ Years & $\mathbf{3 5}$ & $\mathbf{3 5 \%}$ \\
\cline { 2 - 4 } & $\mathbf{5 0 - 6 4}$ Years & $\mathbf{1 7}$ & $\mathbf{1 7 \%}$ \\
\cline { 2 - 4 } & $\mathbf{6 5}$ Years and older & $\mathbf{0}$ & $\mathbf{0 \%}$ \\
\hline \multirow{3}{*}{ Education Level } & Undergraduate & $\mathbf{2 6}$ & $\mathbf{2 6 \%}$ \\
\cline { 2 - 4 } & Graduate & $\mathbf{4 6}$ & $\mathbf{4 6 \%}$ \\
\cline { 2 - 4 } & Student & $\mathbf{2 8}$ & $\mathbf{2 8 \%}$ \\
\hline \multirow{3}{*}{ Occupation } & Business & $\mathbf{0}$ & $\mathbf{0 \%}$ \\
\cline { 2 - 4 } & Academic & $\mathbf{5}$ & $\mathbf{5 \%}$ \\
\cline { 2 - 4 } & Medical & $\mathbf{0}$ & $\mathbf{0 \%}$ \\
\cline { 2 - 4 } & Housewife & $\mathbf{5 5}$ & $\mathbf{5 5 \%}$ \\
\cline { 2 - 4 } & Others & $\mathbf{4 5}$ & $\mathbf{4 5 \%}$ \\
\hline
\end{tabular}

Table 4 shows the distribution of respondents based on gender, age, educational status and occupation for patients admitted during the study period. A majority of the respondents (85\%) were female, with only $15 \%$ of respondents being male. A majority of the respondents (48\%) were between 18-25 years of age, with 35\% of respondents being between 26-49 years, and $17 \%$ being between 50-65 years. A majority of the respondents $(46 \%)$ were graduates, $28 \%$ s were students, while the lowest number were undergraduates $(26 \%)$. A majority of the respondents $(55 \%)$ were housewives, only $5 \%$ of respondents were academics, while the rest $(45 \%)$ had other occupations.

\subsection{Analysing the relationship between the independent and dependent variables}

In this section the researcher will test the research hypotheses to explore the relationship between the independent variables (Patient 
Education Program, Learning Methods, Physicians' and Nurses' Roles, Patients' and Families' Knowledge) and the dependent variable Hospital Admissions.

HA 1: There is a significant relationship between Patient Education Program and Hospital Admissions.

Table 5: Patient Education Program means, SDs, ranks, $\mathbf{X}^{2}$ and p-values

\begin{tabular}{|c|l|c|c|c|c|c|c|}
\hline Q\# & $\begin{array}{l}\text { Patient Education } \\
\text { Program } \\
\text { Statements }\end{array}$ & Mean & SD & Rank & $\begin{array}{c}\text { Chi- } \\
\text { Square }\end{array}$ & $\begin{array}{c}\text { Degree } \\
\text { of } \\
\text { Freedom }\end{array}$ & $\begin{array}{l}\text { p- } \\
\text { value }\end{array}$ \\
\hline 1 & $\begin{array}{l}\text { I have had asthma } \\
\text { education. }\end{array}$ & 3.52 & 1.35 & $3^{\text {rd }}$ & 41.00 & 4 & 0.000 \\
\hline $\begin{array}{l}\text { My doctor has } \\
\text { provided me with } \\
\text { educational } \\
\text { material about my } \\
\text { disease. }\end{array}$ & 3.36 & 1.17 & $4^{\text {th }}$ & 51.71 & 4 & 0.000 \\
\hline 3 & $\begin{array}{l}\text { I have been } \\
\text { educated about the } \\
\text { use of inhalers. }\end{array}$ & 3.83 & 1.26 & $2^{\text {nd }}$ & 86.74 & 4 & 0.000 \\
\hline 4 & $\begin{array}{l}\text { I have been } \\
\text { educated about } \\
\text { asthma medications. }\end{array}$ & 4.46 & 1.31 & $1^{\text {st }}$ & 92.35 & 4 & 0.000 \\
\hline $\begin{array}{l}\text { I have been } \\
\text { educated about the } \\
\text { use of peak flow } \\
\text { meters and holding } \\
\text { chambers. }\end{array}$ & 3.21 & 1.08 & $5^{\text {th }}$ & 48.96 & 4 & 0.000 \\
\hline & & 3.67 & 1.23 & Agree & 64.15 & 4 & 0.000 \\
\hline
\end{tabular}

Five statements were presented to determine the relationship between Patient Education Program and Hospital Admissions, with a standard deviation $(\mathrm{SD})=1.23$ and a total mean of 3.67, indicating "Agree" (perception 3.41-4.2). The mean for each statement ranged between 3.21 and 4.46. The highest mean belongs to the fourth statement, "I have been educated about asthma medications." (mean=4.46), followed by the third, 
"I have been educated about the use of inhalers." (mean=3.83), then first, "I have had asthma education." (mean=3.76), second, "My doctor has provided me with educational material about my disease." (mean=3.36), and finally fifth, "I have been educated about the use of peak flow meters and holding chambers." (mean=3.21).

Table 5 shows the chi-square results of the relationship between Patient Education Program and Hospital Admissions. The results were significant, $\mathrm{X} 2(4, \mathrm{~N}=100)=41.00,48.96,51.71,86.74,92.35$, with $\mathrm{p}<0.001$ and the overall X2 $(4, N=100)=61.15, p<0.001$. Since the chi-square values are greater than the critical chi-square value $=18.5$ at $\mathrm{df}=4$ crossed with $\mathrm{p}=$ 0.001, the alternating (actual) hypothesis (HA 1), which stated that "There is a significant relationship between Patient Education Program and Hospital Admissions", is accepted.

In this case Patient Education Program and Hospital Admissions are not independent but are dependent on each other. All statements were placed in a positive Likert Scale format and the results indicated "Agree". Our findings were in agreement with studies who found that asthma patients should engage in educational programs that show them the correct measures to put in place to reduce exacerbations that limit their quality of life. Such programs are essential to ensure that patients reduce their admission rates. ${ }^{[12]}$

HA 2: There is a significant relationship between Learning Methods and Hospital Admissions. 
Table 6: Learning methods

\begin{tabular}{|c|c|c|c|c|c|c|c|}
\hline $\begin{array}{l}\mathbf{Q} \\
\#\end{array}$ & $\begin{array}{l}\text { Learning Methods } \\
\text { Statements }\end{array}$ & Mean & SD & Rank & $\begin{array}{l}\text { Chi- } \\
\text { Square }\end{array}$ & $\begin{array}{c}\begin{array}{c}\text { Degree } \\
\text { of } \\
\text { Freedom }\end{array} \\
\end{array}$ & $\begin{array}{c}\text { p- } \\
\text { value }\end{array}$ \\
\hline 1 & $\begin{array}{l}\text { I know how to use } \\
\text { my inhalers } \\
\text { properly. }\end{array}$ & 3.93 & 1.28 & $\mathbf{1}^{\text {st }}$ & 65.53 & 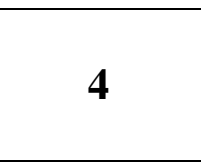 & 0.000 \\
\hline 2 & $\begin{array}{l}\text { I am confident that } \\
\text { I know the } \\
\text { difference between } \\
\text { my reliever and my } \\
\text { preventer inhalers. }\end{array}$ & 3.51 & 1.25 & $3^{\text {rd }}$ & 24.35 & 4 & 0.000 \\
\hline 3 & $\begin{array}{l}\text { I use a spacer (tube } \\
\text { that attaches to the } \\
\text { inhaler) with my } \\
\text { inhaler. }\end{array}$ & 3.40 & 1.19 & $5^{\text {th }}$ & 44.15 & 4 & 0.000 \\
\hline 4 & $\begin{array}{l}\text { I know how to } \\
\text { control my asthma } \\
\text { by looking for a low } \\
\text { peak flow reading. }\end{array}$ & 3.44 & 1.23 & $4^{\text {th }}$ & 43.82 & 4 & 0.000 \\
\hline 5 & $\begin{array}{l}\text { I rinse my mouth } \\
\text { after using my } \\
\text { preventer. }\end{array}$ & 3.54 & 1.41 & $2^{\text {nd }}$ & 62.20 & 4 & 0.000 \\
\hline & Total & 3.56 & 1.27 & Agree & 48.01 & 4 & 0.000 \\
\hline
\end{tabular}

Five statements were presented to determine the relationship between Learning Methods and Hospital Admissions, with a standard deviation $(\mathrm{SD})=1.27$ and a total mean of 3.56, indicating "Agree" (perception 3.41-4.2). The mean for each statement ranged between 3.40 and 3.93. The highest mean belongs to the first statement, "I know how to use my inhalers properly." (mean=3.93), followed by the fifth, "I rinse my mouth after using my preventer." (mean=3.54), then second, "I am confident that I know the difference between my reliever and my preventer inhalers." (mean=3.51), fourth, "I know how to control my asthma by looking for a low peak flow reading." (mean=3.44), and finally third, "I use a spacer (tube that attaches to the inhaler) with my inhaler." (Mean=3.40). 
Table 6 shows the chi-square results of the relationship between Learning Methods and Hospital Admissions. The results were significant, $\mathrm{X} 2(4, \mathrm{~N}=100)=24.34,43.82,44.15,62.20,65.53$ with $\mathrm{p}<0.001$ and the overall X2 $(4, N=100)=48.01, p<0.001$. Since the chi-square values are greater than the critical chi-square value $=18.5$ at $\mathrm{df}=4$ crossed with $\mathrm{p}=$ 0.001 , the alternating (actual) hypothesis (HA 2), which stated that "There is a significant relationship between Learning Methods and Hospital Admissions", is accepted.

In this case Learning methods and Hospital Admissions are not independent but are dependent on each other. All statements were placed in a positive Likert Scale format indicating "Agree". Our findings were in agreement with studies who found that asthma patients should be educated about the importance of taking their chronic management medications as they will help to keep them healthy and reduce the adverse risks of the disease. ${ }^{[18]}$

HA 3: There is a significant relationship between Physicians' and Nurses' roles and Hospital Admissions. 
Table 7: Physicians' and Nurses' Roles

\begin{tabular}{|c|l|c|c|c|c|c|c|}
\hline Q\# & $\begin{array}{l}\text { Physicians' and } \\
\text { Nurses' Roles } \\
\text { Statements }\end{array}$ & Mean & SD & Rank & $\begin{array}{c}\text { Chi- } \\
\text { Square }\end{array}$ & $\begin{array}{c}\text { Degree } \\
\text { of } \\
\text { Freedom }\end{array}$ & $\begin{array}{c}\text { p- } \\
\text { value }\end{array}$ \\
\hline 1 & $\begin{array}{l}\text { I have a written plan } \\
\text { from my doctor. }\end{array}$ & 3.62 & 1.25 & $4^{\text {th }}$ & 54.87 & 4 & 0.000 \\
\hline 2 & $\begin{array}{l}\text { My doctor has } \\
\text { assessed my disease } \\
\text { with a peak flow } \\
\text { meter. }\end{array}$ & 3.27 & 1.28 & $7^{\text {th }}$ & 76.29 & 4 & 0.000 \\
\hline 3 & $\begin{array}{l}\text { My doctor has advised } \\
\text { me about precautions } \\
\text { while using inhalers. }\end{array}$ & 3.45 & 1.20 & $5^{\text {th }}$ & 69.87 & 4 & 0.000 \\
\hline 4 & $\begin{array}{l}\text { My doctor has told me } \\
\text { what the early signs of } \\
\text { worsening asthma are. }\end{array}$ & 3.02 & 1.21 & $6^{\text {rd }}$ & 65.24 & 4 & 0.000 \\
\hline 5 & $\begin{array}{l}\text { The nurse has advised } \\
\text { me to use a peak flow } \\
\text { meter at home. }\end{array}$ & 3.92 & .98 & $2^{\text {nd }}$ & 58.95 & 4 & 0.000 \\
\hline $\begin{array}{l}\text { The nurse has checked } \\
\text { with me to ensure that } \\
\text { I am following my } \\
\text { medication protocols } \\
\text { accurately and that I } \\
\text { am not experiencing } \\
\text { any adverse } \\
\text { symptoms. }\end{array}$ & 3.97 & 1.13 & $1^{\text {st }}$ & 48.56 & 4 & 0.000 \\
\hline 7 & $\begin{array}{l}\text { The nurse has asked if } \\
\text { I had any problems, } \\
\text { concerns, or questions. }\end{array}$ & 3.75 & 1.09 & $3^{\text {rd }}$ & 49.51 & 4 & 0.000 \\
\hline \begin{tabular}{l} 
Total \\
\hline
\end{tabular} & 3.57 & 1.16 & Agree & 60.47 & 4 & 0.000 \\
\hline
\end{tabular}

Seven statements were presented to determine the relationship between Physicians' and Nurses' Roles and Hospital Admissions, with a standard deviation $(\mathrm{SD})=1.16$ and a total mean of 3.57, indicating "Agree" (perception 3.41-4.2). The mean for each statement ranged between 3.27 3.97, the highest mean belonging to the sixth statement, "The nurse has checked with me to ensure that I am following my medication protocols accurately and that I am not experiencing any adverse symptoms." 
(mean=3.97), followed by the fifth, "The nurse has advised me to use a peak flow meter at home." (mean=3.92), seventh, "The nurse has asked if I had any problems, concerns, or questions." (mean=3.75), first, "I have a written plan from my doctor." (mean=3.62), third, "My doctor has advised me about precautions while using inhalers." (mean=3.47), fourth, "My doctor has told me what the early signs of worsening asthma are." (mean=3.02), and finally second, "My doctor has assessed my disease with a peak flow meter." (mean=3.27).

Table 7 shows the chi-square results of the relationship between Physicians' and Nurses' Roles and Hospital Admissions. The results were significant, $\mathrm{X} 2(4, \mathrm{~N}=100)=48.56,49.51,54.87,58.95,65.24,69.87$, 76.29 , with $\mathrm{p}<0.001$ and the overall $\mathrm{X} 2(4, \mathrm{~N}=100)=60.47, \mathrm{p}<0.001$. Since the chi-square values are greater than the critical chi-square value $=$ 18.5 at $\mathrm{df}=4$ crossed with $\mathrm{p}=0.001$, the alternating (actual) hypothesis (HA 3), which stated that "There is a significant relationship between Physicians' and Nurses' Roles and Hospital Admissions", is accepted.

In this case Physicians' and Nurses' Roles and Hospital Admissions are not independent but are dependent on each other. All statements were placed in a positive Likert Scale format indicating "Agree". Our findings were in agreement with studies who found that having physicians and nurses who are responsible for ensuring patients adhere to medication and for conducting follow-ups is essential for regulating hospital admissions. [14] 
HA 4: There is a significant relationship between Patients' and Families' Knowledge and Hospital Admissions.

Table 8: Patients' and Families' Knowledge

\begin{tabular}{|c|l|c|c|c|c|c|c|}
\hline Q\# & $\begin{array}{l}\text { Patients' and Families' } \\
\text { Knowledge Statements }\end{array}$ & Mean & SD & Rank & $\begin{array}{c}\text { Chi- } \\
\text { Square }\end{array}$ & $\begin{array}{c}\text { Degree } \\
\text { of } \\
\text { Freedom }\end{array}$ & $\begin{array}{c}\text { p- } \\
\text { value }\end{array}$ \\
\hline 1 & $\begin{array}{l}\text { I know which things } \\
\text { make my asthma get } \\
\text { worse. }\end{array}$ & 3.26 & 1.22 & $5^{\text {th }}$ & 46.55 & 4 & 0.000 \\
\hline 2 & $\begin{array}{l}\text { I know how to avoid } \\
\text { things that make my } \\
\text { asthma worse. }\end{array}$ & 3.44 & 1.35 & $3^{\text {rd }}$ & 67.84 & 4 & 0.000 \\
\hline 3 & $\begin{array}{l}\text { I know what each of my } \\
\text { medications does. }\end{array}$ & 3.48 & 1.02 & $2^{\text {nd }}$ & 42.37 & 4 & 0.000 \\
\hline 4 & $\begin{array}{l}\text { I know when my asthma } \\
\text { is getting worse. }\end{array}$ & 3.88 & 1.17 & $1^{\text {st }}$ & 52.85 & 4 & 0.000 \\
\hline 5 & $\begin{array}{l}\text { I am confident I can } \\
\text { usually manage my } \\
\text { asthma symptoms. }\end{array}$ & 3.27 & 1.29 & $4^{\text {th }}$ & 43.86 & 4 & 0.000 \\
\hline $\begin{array}{l}\text { I am confident I can } \\
\text { prevent my asthma } \\
\text { symptoms from } \\
\text { becoming severe. }\end{array}$ & 3.20 & 1.35 & $6^{\text {th }}$ & 54.65 & 4 & 0.000 \\
\hline \multicolumn{2}{l}{ Total } & 3.42 & 1.23 & Agree & 51.35 & 4 & 0.000 \\
\hline
\end{tabular}

Six statements were presented to determine the relationship between Patients' and Families' Knowledge and Hospital Admissions, with a standard deviation $(\mathrm{SD})=1.23$ and a total mean of 3.42, indicating "Agree" (perception 3.41-4.2). The mean for each statement ranged between $3.20-$ 3.88, the highest mean belonging to the fourth statement, "I know when my asthma is getting worse." (mean=3.88), followed by the third, "I know what each of my medications does." (mean=3.48), second, "I know how to avoid things that make my asthma worse." (mean=3.44), fifth, "I am confident I can usually manage my asthma symptoms." (mean=3.27), first, "I know which things make my asthma get worse." (mean=3.26), and finally sixth, 
"I am confident I can prevent my asthma symptoms from becoming severe." (mean=2.20).

Table 8 shows the chi-square results of the relationship between Patients' and Families' Knowledge and Hospital Admissions. The results were significant, $\mathrm{X} 2(4, \mathrm{~N}=100)=42.37,43.86,46.55,52.85,54.65,67.84$, with $\mathrm{p}<0.001$ and the overall X2 $(4, N=100)=51.35, \mathrm{p}<0.001$. Since the chi-square values are greater than the critical chi-square value $=18.5$ at $\mathrm{df}$ $=4$ crossed with $\mathrm{p}=0.001$, the alternating (actual) hypothesis (HA 4), which stated that "There is a significant relationship between Patients' and Families' Knowledge and Hospital Admissions", is accepted.

In this case the Patients' and Families' Knowledge and Hospital Admissions are not independent but are dependent on each other. All statements were placed in a positive Likert Scale format indicating "Agree". Our findings were in agreement with studies who found that patients' families should be educated about the effectiveness of the patient taking the drugs provided in order to eliminate the chances of the disease causing adverse outcomes. ${ }^{[19]}$

Table 9: Hospital Admissions

\begin{tabular}{|c|l|c|c|c|}
\hline Q\# & Hospital Admission Statements & Mean & SD & Rank \\
\hline 1 & $\begin{array}{l}\text { I have been admitted to hospital within } \\
\text { the last month. }\end{array}$ & 3.56 & 1.26 & $2^{\text {nd }}$ \\
\hline 2 & $\begin{array}{l}\text { I have been to the emergency room due } \\
\text { to asthma since my last visit to hospital. }\end{array}$ & 2.96 & 1.32 & $4^{\text {th }}$ \\
\hline 3 & $\begin{array}{l}\text { I have fallen since my previous } \\
\text { admission. }\end{array}$ & 3.44 & 1.48 & $3^{\text {rd }}$ \\
\hline 4 & $\begin{array}{l}\text { I have been to another facility after being } \\
\text { discharged from my previous admission. }\end{array}$ & 3.94 & 1.14 & $1^{\text {st }}$ \\
\hline \multicolumn{2}{|r|}{ Total } & 3.48 & 1.30 & Agree \\
\hline
\end{tabular}


Four statements were presented to determine the dependent variable, Hospital Admissions, with a standard deviation $(\mathrm{SD})=1.3$ and a total mean of 3.48, indicating "Agree" (perception 3.41-4.2). The mean for each statement ranged between $2.96-3.94$, the highest mean belonging to the fourth statement, "I have been to another facility after being discharged from my previous admission." (mean=3.94), followed by the first, "I have been admitted to hospital within the last month." (mean=3.56), third, "I have fallen since my previous admission." (mean=3.44), then finally second, "I have been to the emergency room due to asthma since my last visit to hospital." (mean=2.96).

Our findings were in agreement with studies who found that those patients who were discharged from hospital with medication and followed up with an action plan were admitted as an emergency less frequently than those who did not follow the plan. ${ }^{[20]}$

Table 10: The relationship between the independent and dependent variables

\begin{tabular}{|c|l|c|c|c|c|c|c|}
\hline Q\# & $\begin{array}{l}\text { Independent } \\
\text { variables }\end{array}$ & $\begin{array}{c}\text { Mea } \\
\text { n }\end{array}$ & SD & Rank & $\begin{array}{c}\text { Chi- } \\
\text { Square }\end{array}$ & $\begin{array}{c}\text { Degree } \\
\text { of } \\
\text { Freedom }\end{array}$ & $\begin{array}{c}\text { p- } \\
\text { value }\end{array}$ \\
\hline 1 & $\begin{array}{l}\text { Patient Education } \\
\text { Program }\end{array}$ & 3.67 & 1.23 & $1^{\text {st }}$ & 64.15 & 4 & $\mathbf{0 . 0 0 0}$ \\
\hline 2 & Learning Methods & $\mathbf{3 . 5 6}$ & 1.27 & $3^{\text {rd }}$ & 48.01 & 4 & $\mathbf{0 . 0 0 0}$ \\
\hline 3 & $\begin{array}{l}\text { Physicians' and } \\
\text { Nurses' Roles }\end{array}$ & 3.57 & 1.16 & $2^{\text {nd }}$ & 60.47 & 4 & 0.000 \\
\hline 4 & $\begin{array}{l}\text { Patients' and } \\
\text { Families' } \\
\text { knowledge }\end{array}$ & $\mathbf{3 . 4 2}$ & 1.23 & $4^{\text {th }}$ & 51.35 & 4 & $\mathbf{0 . 0 0 0}$ \\
\hline
\end{tabular}

Table 10 shows the perception levels and ranking among the independent variables (Patient Education Program, Learning Methods, Physicians' and Nurses' Roles, and Patients' and Families' Knowledge). The respondents 
show a satisfied (positive) perception in general, with mean $=3.56$, $\mathrm{SD}=1.22$.

Among the independent variables, Patient Education Program ranked first with mean $=3.67, \mathrm{SD}=1.23$, followed by Physicians' and Nurses' Roles in second place with mean $=3.57, \mathrm{SD}=1.16$, Learning Methods in third place with mean $=3.56, \mathrm{SD}=1.27$, while Patients' and Families' Knowledge was ranked last with mean $=3.42, \mathrm{SD}=1.23$.

\section{Conclusion and Recommendations}

The major purpose of this research is to explore the influence of asthma patient education on the reduction of hospital admissions. It also seeks to explain how better educational outcomes can reduce the number of hospital admissions. Rises in hospital admissions increase the need for facilities for accepting patients, leading to greater efficiency. Many studies have been conducted to understand the development and management of the disease, and how to prevent its adverse outcomes. Various scholars have argued that patient education programs are among the most relevant practices to reduce hospital admissions for asthma. Moreover, learning methods have been proposed to improve asthma maintenance. The study has applied various methods to obtain and examine data, and present it for recommendation. Questionnaires have been used to obtain data for analysis. Statistical methods have been utilized to obtain sample data and analyse it using descriptive statistics. Various instruments have been used to assure data validity and reliability. Data analysis has been employed as a means of examining the obtained information to clarify the presented hypotheses. Statistical methods of data analysis have been integrated to identify factors such as means, coefficients of data, correlations and standard deviations. The analysis has 
been used to present information concerning the research objective, the findings and their significance. These findings elaborate on whether the hypotheses presented are correct. The conclusion presents the objectives of the study, the data analysis, information regarding whether or not the hypotheses have been proven and recommendations on how the data can be used for further studies. It also indicates the means of applying the knowledge gained to improve asthma patient education to help to reduce hospital readmissions.

\section{Conclusion:}

- Patients should be engaged in educational programs to explain the importance of asthma medications. This reduces complications and hospital admission rates.

- Instructions should be provided regarding the correct use of tools and strategies in order to avoid the possibility of adverse risks.

- The role of nurses and physicians in controlling asthma in patients has a link with reductions in hospitalization by ensuring that patients have an understanding of the effects and effectiveness of medication on their health.

- Providing patients' families with theoretical knowledge and practical expertise improves the efficiency and quality of health care offered by physicians and nurses, thus reducing hospital admissions through effective disease management at home.

\section{Recommendations:}

- Introduce new educational programs in order to provide more patients with information regarding medications and the use of asthma-related tools such as training classes, flyers and magazines. 
- Develop learning methods by helping patients to understand care, medications, the correct use of tools and warning signs delivered in a format that includes demonstrations of care, teach-back questions and assessments, and that facilitates provider communications. Explain strategies to be used in case of an attack.

- Develop an action plan for patients linked to the Electronic Medical Record that is accessible to nurses and physicians, in order to monitor the progress of the patients remotely and ensure the plan is followed.

- Enhance patients' and families' knowledge by offering full participation in their own care and encourage them to partner with clinicians to increase their adherence to disease management and accountability for their own health. 


\section{References}

[1] Donques AA, Alaki E, Almazyad W, Almutairi A. Knowledge and Perception of Asthmatic Patients and their Family towards Asthma Disease and Management in King Saud Medical City, Riyadh, KSA. J Clin Respir Dis Care. 2017; 3(1): 1-5. https://doi.org/10.4172/2472$\underline{1247.1000128}$

[2] Al-Ghamdi BR, Mahfouz AA, Abdelmoneim I, Khan MY, Daffallah AA. Altitude and bronchial asthma in south-western Saudi Arabia. East Mediterr Health J. 2008; 14: 17-23.

[3] Alotaibi GA. Asthma control and self-management: The role of asthma $\begin{array}{llllll}\text { education. Saudi } J \text { Health } & \text { Sc. 2015; 4(1): 16-22. }\end{array}$ https://doi.org/10.4103/2278-0521.151404

[4] Cowie RL, Cowie RL, Underwood MF, Revitt SG, Field SK. Predicting emergency department utilization in adults with asthma: a cohort study. Journal of Asthma. 2001; 38(2): 179-184. https://doi.org/10.1081/JAS-100000037

[5] Prabhakaran L, Lim G, Abisheganaden J, Chee CBE, Choo YM. Impact of an asthma education programme on patients' knowledge, inhaler technique and compliance to treatment. Singapore medical journal. 2006; 47(3): 225-231.

[6] Kambli S. Asthma patient's knowledge regarding diagnosis and treatment. International Journal of Science and Research. 2012; 3(6): 1871-1876.

[7] Smith S, Mitchell C, Bowler S. Standard versus patient-centred asthma education in the emergency department: a randomised study. European Respiratory Journal. 20088; 31(5): 990-997. https://doi.org/10.1183/09031936.00053107

[8] Perneger TV, Sudre P, Muntner P, Uldry C, Courteheuse C, Naef AF, Jacquemet S, Nicod L, Rochat T, Assal JP. Effect of patient education on self-management skills and health status in patients with asthma: a 
randomized trial. The American journal of medicine. 2002; 113(1): 7 14. https://doi.org/10.1016/S0002-9343(02)01136-1

[9] Adams RJ, Smith BJ, Ruffin, RE. Factors associated with hospital admissions and repeat emergency department visits for adults with $\begin{array}{llll}\text { asthma. } & \text { Thorax. } & \text { 2000; } & \text { 55(7): }\end{array}$ https://doi.org/10.1136/thorax.55.7.566

[10] Fontes MJ, Affonso AG, Calazans G, Andrade CRD, Lasmar LM, Nader CM, Camargos PA. Impact of an asthma management program on hospitalizations and emergency department visits. Jornal de pediatria. 2011; 87(5): 412-418. https://doi.org/10.2223/JPED.2129

[11] Mishra R, Kashif M, Venkatram S, George T, Luo K, Diaz-Fuentes G. Role of Adult Asthma Education in Improving Asthma Control and Reducing Emergency Room Utilization and Hospital Admissions in an Inner City Hospital. Canadian respiratory journal. 2017. Available from: https://www.hindawi.com/journals/crj/2017/5681962/

[12] Al-Muhsen S, Horanieh N, Dulgom S, Al Aseri Z, Vazquez-Tello A, Halwani R, Al-Jahdali H. Poor asthma education and medication compliance are associated with increased emergency department visits by asthmatic children. Annals of thoracic medicine. 2015; 10(2): 123. https://doi.org/10.4103/1817-1737.150735

[13] Pinnock H. Supported self-management for asthma. Breathe. 2015; 11(2): 98-109. https://doi.org/10.1183/20734735.015614

[14] Axelsson M, Ekerljung L, Lundbäck B. The significance of asthma follow-up consultations for adherence to asthma medication, asthma medication beliefs, and asthma control. Nursing research and practice. 2015. https://doi.org/10.1155/2015/139070

[15] Zhao J, Shen K, Xiang L, Zhang G, Xie M, Bai J, Chen Q. The knowledge, attitudes and practices of parents of children with asthma in 29 cities of China: a multi-center study. BMC pediatrics. 2013: 13(1): 20. https://doi.org/10.1186/1471-2431-13-20 
[16] Carrillo G, Perez-Patron MJ, Lucio RL, Cabrera L, Trevino A, Xu X, Mier N. The Benefits and challenges of Managing asthma in hispanic Families in south Texas: a Mixed-Methods study. Frontiers in public health. 2017; 5: 150. https://doi.org/10.3389/fpubh.2017.00150

[17] Fraenkel JR, Wallen NE, Hyun HH. How to design and evaluate research in education (Vol. 7). New York: McGraw-Hill; 1993.

[18] Sari N, Osman M. The effects of patient education programs on medication use among asthma and COPD patients: a propensity score matching with a difference-in-difference regression approach. BMC $\begin{array}{lllll}\text { health } & \text { services } & \text { research. } 2015 ; & 15(1): & 332 .\end{array}$ https://doi.org/10.1186/s12913-015-0998-6

[19] Kelso JM. Do written asthma action plans improve outcomes?. Pediatric allergy, immunology, and pulmonology. 2016; 29(1): 2-5. https://doi.org/10.1089/ped.2016.0634

[20] Hatoun J, Bair-Merritt M, Cabral H, Moses J. Increasing medication possession at discharge for patients with asthma: the meds-in-hand project. Pediatrics, peds-2015. 2016. Available from: http://pediatrics.aappublications.org/content/pediatrics/137/3/e2015046 1.full.pdf 
APPENDIX (A)

\begin{tabular}{|r|}
\hline Asthma Education Questionnaire \\
\hline Part 1- Personal Information (Demographic Profile) \\
\hline
\end{tabular}

a) What's your gender?

Male $\square \quad$ Female $\square$

b) How old are you?

18-25 years $\square \quad$ 26-49 years $\square \quad$ 50-64 years $\square \quad 65$ and older $\square$

c) What's your

Undergraduate $\square \quad$ Graduate $\square \quad$ Student $\square$

educational

Qualification?

Business $\square \quad$ Academic $\square \quad$ Medical $\square$

d) What's your

occupation?

Housewives $\square$

Others $\square$

Part 2 - Patients' and Families' Knowledge

$\begin{array}{ccccc}\begin{array}{c}\text { Strongly } \\ \text { Agree }\end{array} & \text { Agree } & \text { Neutral } & \text { Disagree } & \begin{array}{c}\text { Strongly } \\ \text { Disagree }\end{array}\end{array}$

a)I know which things make my asthma get worse.

b)I know how to avoid things that make my asthma worse.

c) I know what each of my medications does.

d)I know when my asthma is getting worse.

e) I am confident I can usually manage my asthma symptoms.

f) I am confident I can prevent my asthma symptoms from becoming severe. 


\section{Part 3 - Learning Methods}

g) I know how to use my inhalers properly.

h) I am confident that I know the difference between my reliever and my preventer inhalers.

i) I use a spacer (tube that attaches to the inhaler) with my inhaler.

j) I know how to control my asthma by looking for a low peak flow reading.

k) I rinse my mouth after using my preventer.

\section{Part 4 - Physicians' and Nurses' Roles}

I) I have a written plan from my doctor.

m) My doctor has assessed my disease with a peak flow meter.

n) My doctor has advised me about precautions while using inhalers.

o) My doctor has told me what the early signs of worsening asthma are.

p) The nurse has advised me to use a peak flow meter at home.

q) The nurse has checked with me to ensure that I am following my medication protocols accurately and that $I$ am not experiencing any adverse symptoms.

r) The nurse has asked if I had any problems, concerns, or questions. 


\section{Part 5 - Patient Education Program}

s) I have had asthma education.

t) My doctor has provided me with educational material about my disease.

u)I have been educated about the use of inhalers.

v)I have been educated about asthma medications.

w) I have been educated about the use of peak flow meters and holding chambers.

\section{Part 6 - Hospital Admission}

a) I have been admitted to hospital within the last month.

b) I have been to the emergency room due to asthma since my last visit to hospital.

c) I have fallen since my previous admission.

d) I have been to another facility after being discharged from my previous admission. 